\title{
IDENTIFIKASI LIMBAH PALM OIL MILL EFFLUENT (POME) MENGGUNAKAN BIOSENSOR BERBASIS ALGA
}

\author{
Dina Maryani, Lazuardi Umar* \\ ${ }^{1}$ Program Studi S1 Fisika FMIPA Universitas Riau, J1. Prof. Muchtar Luthfi Pekanbaru, 28293, Indonesia \\ *e-mail: lazuardi@unri.ac.id
}

\begin{abstract}
ABSTRAK
Palm Oil Mill Effluent (POME) merupakan limbah minyak kelapa sawit yang memiliki kadar Chemical Oxygen Demand (COD) dan Biochemical Oxygen Demand (BOD) yang tinggi sehingga merusak ekosistem perairan serta menurunkan kadar oksigen terlarut (dissolved oxygen, DO). Berdasarkan hal tersebut dilakukan identifikasi POME yang jatuh kebadan air mempergunakan biosensor amperometris tipe Biochip-G denganalga Chlorella sp. sebagai bioreseptor.Biosensor mengukurperubahan arus akibat metabolismesel alga melaluimekanisme fotosintesis yang akan menghasilkan potensial keluaran. Potensial ini proporsional dengan kadar DOdari Chlorella sp. pada proses fotosintesis ketika POME berada pada lingkungan alga. Identifikasi POME dilakukan dengan memberikan alga cahaya artifisial LED putih 380-780 nm dengan tingkat variasi konsentrasi POME sebanyak 10\%, 20\%, dan 30\%. Berdasarkan pengukuran kadar oksigen terlarut (DO) menghasilkan nilai DO sebesar $174.15 \%, 154.66 \%$, dan $138.98 \%$ serta nilai sensitivitas sebesar 4mV/\% POME.
\end{abstract}

Kata Kunci: Biosensor; Palm Oil Mill Effluent; Alga; Oksigen terlarut

ABSTRACT

[Title: IdentificationPalm Oil MillEffluent (POME) Using Biosensor Based Algae] Palm Oil Mill Effluent (POME) is a palm oil wastethat has high levels of Chemical OxygenDemand (COD) and Biochemical Oxygen Demand (BOD) which damages aquatic ecosystems and reduces dissolved oxygen (DO) levels. However, POME has nutrients for algae cells to produce oxygen. Based on this, it is necessary to identify POME that falls into water bodies based on photosynthesis of Chlorella sp.using biosensors. Biosensors have been widely developed in environmental applications by looking at dissolved oxygen levels as water quality. This study uses a biosensor with anamperometric sensor principletype Biochip-G. The amperometric sensor measured the change in current of the reduction andoxidation reactions and produced a measurable output potential. The measured output potential waste dissolve doxygen level from the addition of POME to Chlorella sp.when photosynthesis occurs. Identification of POME based on the photosynthesis process of Chlorella sp.using artificial white LED light 380-780 nm with varying levels of POME concentration as much as $10 \%$, 20\%, and 30\%. Based on the measurement of dissolved oxygen (DO) levels, the DO values were $174.15 \%, 154.66 \%, 138.98 \%$ and the sensitivity values were $4 \mathrm{mV} / \%$ POME.

Keywords: Biosensors; Palm Oil Mill Effluent; Algae; Dissolved oxygen

\section{PENDAHULUAN}

Palm Oil Mill Effluent (POME) merupakan limbah sawit yang dibuang ke sungai dengan karakteristik berwarna kecoklatanyang memiliki kekeruhanyang tinggi akibat kandungan bahan organik dan padatan tersuspensi (A. L. Ahmad et al., 2006). Produksi untuk satu ton minyak sawit membutuhkan 5.0-7.5 ton air dan menghasilkan 50\% limbah POME (Vijayaraghavan \& Ahmad, 2006). Limbah POME memiliki kandungan Chemical Oxygen Demand (COD) dan Biochemical Oxygen Demand (BOD) yang tinggi serta terdapat kandungan mineral seperti karbon (C), nitrogen (N), dan fosfor (P) yang menyebabkan pencemaran lingkungan pada badan air. Kandungan mineral pada POME dapat digunakan sebagai nutrisi budidaya sel alga dan dapat membersihkan air limbah (A. Ahmad et al., 2016).

Sel alga adalah organisme yang paling cocok dan efisien untuk pengolahan biologis pada air limbah, karena dapat tumbuh di air limbah sehingga mengurangi polutan didalamnya (Altunoz et al., 2020). Alga Chlorella sp. merupakan organisme yang memanfaatkan cahaya matahari untuk mengubah karbondioksida $\left(\mathrm{CO}_{2}\right)$ menjadi karbohidrat dan oksigen $\left(\mathrm{O}_{2}\right)$, serta dapat menyerap banyak senyawa organik dari limbah cair seperti karbon, nitrogen dan fosfor sehingga mampu menjernihkan air limbah 
POME (Kamarudin et al., 2015). Penelitian Emparan (2020) memanfaatkan limbah POME sebagai medium kultur Nannochloropsis sp., namun penelitian ini tidak melihat kadar oksigen terlarut dari metabolisme sel alga. Berdasarkan pemaparan diatas maka padapenelitian ini diteliti pengaruh penambahan POME menggunakan biosensoryang mendeteksi berdasarkan vitalitas alga yang dinyatakan sebagai tingkat oksigen terlarut (Dissolved Oxygen, DO).

Biosensor merupakan sensor yang terdiri dari bioreseptor dan perangkat transduser yang terintegrasi secara independen dan mampu memberikan informasi analitik secara real-time (Karunakaran et al., 2015).Penelitian biosensor menggunakan metabolisme sel alga berbasis sensor amperometris telah dilakukan oleh Umar (2015) untuk memantau pencemaran air menggunakan Crude Palm Oil (CPO) berdasarkan metabolisme sel alga danAjab (2019) memantau lingkungan perairan dengan sensor yang dimodifikasi dengan selulosa dan hidroksiapatit untuk mendeteksi ion timbal pada limbah POME. Namun, pada penelitian ini tidak melihat perubahan kadar oksigen terlarut yang dihasilkan dari vitalitas alga.

Penelitian ini menggunakan biosensor oksigen tipe Clark dengan biochip tipe $\mathrm{G}$ yang dibeli dari cellasys $\mathrm{GmbH}$ (Cellasys, 2014). Biochip ini dapat mengukur kadar oksigen terlarut dengan teknik pengukuran yang mudah serta operasional yang stabil dimana sel alga Chlorella sp. berperan sebagai bioreseptor dan limbah POME sebagai analit. Sumber cahaya artifisial yang digunakan adalah LED putih dengan panjang gelombang 380$780 \mathrm{~nm}$. Alga yang diimobilisasi diamati menggunakan elektroda sensor yang terintegrasi dengan elektroda pengukur ukuran mikro.

\section{METODE}

\section{Alga Chlorella sp. dan Kultivasi}

Penelitian ini menggunakan alga Chlorella sp. yang didapatkan dari Fakultas Perikanan dan Kelautan, Universitas Riau. Chlorella sp. diklasifikasikan ke dalam kategori alga hijau bersel satu.Alga Chlorella sp. dapat tumbuh pada salinitas 0-35 ppt dan masih dapat bertahan hidup pada suhu $40^{\circ} \mathrm{C}$, tetapi tidak tumbuh. Keberadaan Chlorella sp. dalam air limbah sangat penting, karena dapat menjernihkan air limbah dengan menggunakan logam berat dan nutrisi untuk produksi oksigen $\left(\mathrm{O}_{2}\right)$ (Randrianarison \& Ashraf, 2018). Sel Chlorella sp. ditunjukkan pada Gambar 1.

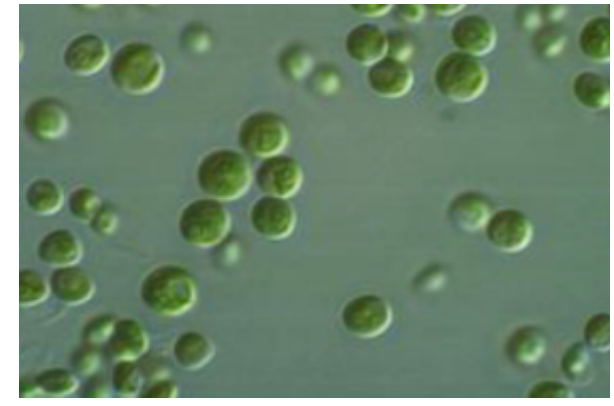

Gambar 1. Alga Chlorella sp.

Pembuatan medium alga dilakukan dengan penambahan 1.87 gram Algae Culture Broth (ACB) dari Sigma AldrichSKU-17124ke dalam $1000 \mathrm{~mL}$ akuades(HiMedia Laboratories, 2015). Campuran medium sel alga dihomogenkan menggunakan shaker inkubator dengan kecepatan $150 \mathrm{rpm}$ selama 15 menit dan diautoklaf selama 2 jam dengan suhu $121^{\circ} \mathrm{C}$. Medium sel alga yang telah dibuat dikultivasi dengan menambahkan Chlorella sp. sebanyak $5 \mathrm{~mL}$. Kultivasi sel Chlorella sp. diberi pencahayaan selama 12 jam ON dan 12 jam OFF dengan bantuan cahaya lampu TL 21 Watt. Setelah 10 hari kultivasi, sel alga dapat dijadikan sampel pengukuran kadar oksigen terlarut jika telah terjadi peningkatan. Pemanenan alga dilakukan ketika sel alga selesai dikultivasi dan dapat disimpan untuk kultivasi alga selanjutnya. Jumlah densitas sel alga dihitung menggunakan Hemocytometer dan dilihat menggunakan Mikroskop Optik XSP-12.

\section{Kalibrasi Biochip-G}

\section{a. Biochip-G}

Biochip-G merupakan perangkat analitis yang diproduksi dari perusahaan cellasys $\mathrm{GmbH}$. Sensor Biochip-G terdiri dari tiga elektroda yaitu Working Electrode (WE), Reference Electrode (RE), dan Auxiliary Electrode (AE). Spesifikasi dari Biochip-G dapat dilihat pada Gambar 2 dan Tabel 1.

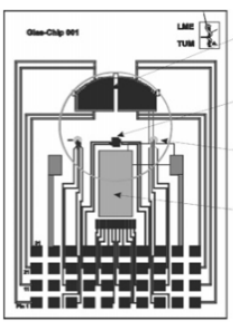

Tabel 1. Spesifikasi Biochip-G

\begin{tabular}{lc}
\multicolumn{2}{c}{ (Cellasys, 2014) } \\
\hline Material & Kaca \\
\hline Elektroda DO & $\sim 3 \mathrm{~mm}^{2}$ \\
\hline $\begin{array}{l}\text { Ukuran } \\
\text { Linear }\end{array}$ & 0 to $120 \% \mathrm{DO}$ \\
\hline Sensitivitas & 1nA $/ \mathrm{pDO} \pm 10 \%$ \\
\hline
\end{tabular}

Gambar 2. Struktur Biochip-G (Wiest et al., 2005)

Dimensi dari Biochip-G yaitu sebesar $33,8 \times 24,0 \times 0,5 \mathrm{~mm}^{3}$ dengan suhu operasi $0{ }^{\circ} \mathrm{C}$ sampai $+80^{\circ} \mathrm{C}$. Elektroda pada Biochip-G memiliki 4 komponen yang dapat digunakan untuk mengukur parameter fisis diantaranya yaitu sensor oksigen amperometris, sensor $\mathrm{pH}$, sensor suhu Pt 1000, dan sensor impedansi (Wiest et al., 2005). Penelitian ini 
menggunakan sensor oksigen amperometris untuk mengukur tingkat oksigen terlarut (DO) dan sebelum pengukuran berlangsung, dilakukan kalibrasi sensor terlebih dahulu untuk menguji elektroda-elektroda sensor agar sesuai dengan standar pengukuran.

\section{b. Kalibrasi Cal0 dan Cal100 Sensor}

Kalibrasi sensor oksigen dilakukan untuk menyesuaikan alat ukur agar sesuai dengan standar pengukuran yang ditentukan. Tahap kalibrasi dilakukan dengan dua cara yaitu pembuatan larutan Cal0 dan Cal100. Cal0 merupakan larutan bebas oksigen yang dibuat dengan menggunakan Natrium Sulfit $\left(\mathrm{Na}_{2} \mathrm{SO}_{3}\right)$ sebanyak 0.05 gram dan dilarutkan kedalam $10 \mathrm{~mL}$ akuades agar air menjadi bebas oksigen. Cal100 merupakan larutan dengan jenuh oksigen yang dibuat menggunakan akuades yang diaerasi agar dalam keadaan saturasi oksigen.

\section{Persiapan Sampel Analit POME}

Sampel analit yang dipergunakan adalah limbah Pabrik Kelapa Sawit dari PTPN V Sei Pagar. Persiapan dilakukan dengan mengencerkan POME menggunakan akuades sebanyak $50 \mathrm{~mL}$, dimana sebelum dilakukan pengenceran, dilakukan pengecekkan terlebih dahulu konsentrasi Chemical Oxygen Demand (COD) menggunakan metode dikromatometri. Pengenceran POME dilakukan dengan pengambilan volume total $50 \mathrm{ml}$ dan dicampur larutan Akuades dengan rasio 10\%, 20\%, dan 30\% seperti pada Gambar 3. Pengecekkan pH juga dilakukan setelah pengenceran menggunakan Indikator $\mathrm{pH}$ paper Merck.

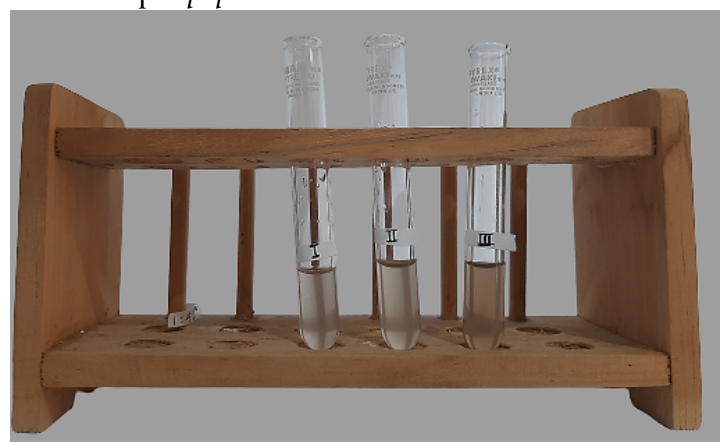

Gambar 3. Pengenceran limbah POME dengan 3 variasi konsentrasi

\section{Vitalitas alga pada penambahan POME}

Sel alga Chlorella sp. dipergunakan pada penelitian ini sebagai bioreseptor dimana metabolisme sel diamati didalam chamber reaksi dari BiochipG.Sampel alga dengan jumlah populasi $26 \times 10^{6}$ sel/mL diimmobilisasi sebanyak $200 \mu \mathrm{L}$ ke dalam chamber. Pengaruh sampel analit diamati dengan memberikan larutan POME ke dalam chamber sebanyak $50 \mu \mathrm{L}$ menggunakan pipet Eppendorf.

\section{Eksperimen Vitalitas Alga Terhadap Penambahan POME}

Set up pengukuran tingkat DO mempergunakan modul biosensor dan komputer dapat dilihat pada Gambar 4. Penelitian ini mempergunakan cahaya artifisial dari LED putih dengan panjang gelombang 380-780 nm, daya maksimum sebesar 3 Watt dan akan memberikan daya photon sebesar 252 photon $/ \mathrm{m}^{2} \mathrm{~s}$. IdentifikasiPOME pada sel alga dilakukan untuk melihat tingkat oksigen terlarut dengan 3 variasi konsentrasi yaitu 10\%, 20\%, dan $30 \%$. Tujuan konsentrasi yang berbeda untuk melihat respon sel alga terhadap zat asing (POME) yang mempengaruhi metabolisme sel yang dinyatakan sebagai tingkat oksigen terlarut sel alga. Identifikasi dilakukan dengan pemberian cahaya LED ON dan OFF selama 500s pada sel alga dan ketika LED ON atau saat sel alga sedang berfotosintesis diberikan limbah POME pada masing-masing konsentrasi. Hasil dari pengukuran ini akan ditampilkan dalam bentuk grafik potensial terhadap waktu pada komputer.

\section{HASIL DAN PEMBAHASAN}

Kalibrasi Cal0 dan Cal100 dilakukan untuk mencari nilai oksigen terlarut (DO). Hasil kalibrasi Cal0 dan Cal100 ditunjukkan pada Gambar 5 menghasilkan potensial keluaran maksimum dan minimum sebesar $2010 \mathrm{mV}$ dan $1774 \mathrm{mV}$. 


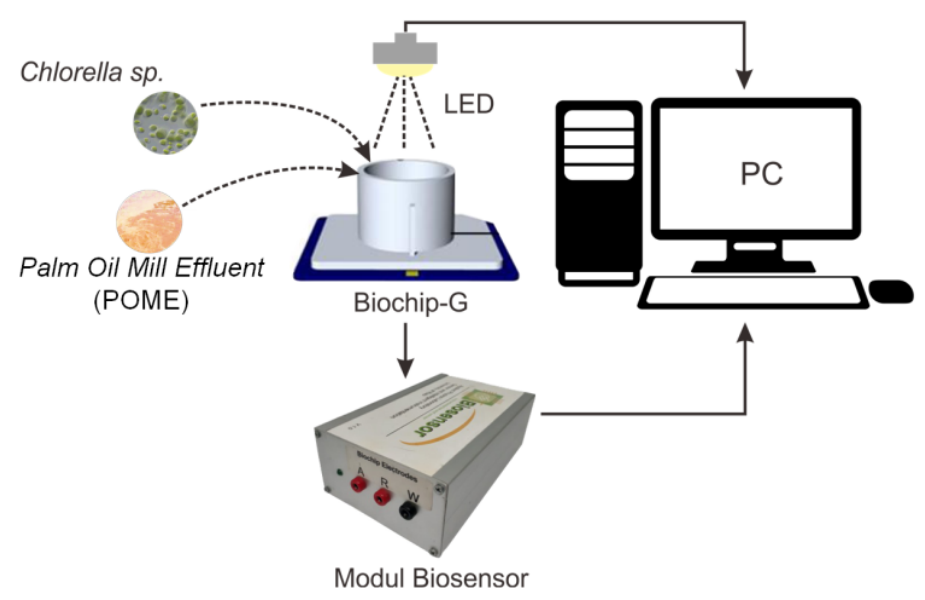

Gambar 4. Set up pengukuran limbah POME

Kalibrasi Cal0 dan Cal100 digunakan sebagai konversi nilai potensial menjadi DO\% pada metabolisme sel dimana dari kurva pada Gambar 5 dimodelkan menjadi Persamaan 1 dan 2.

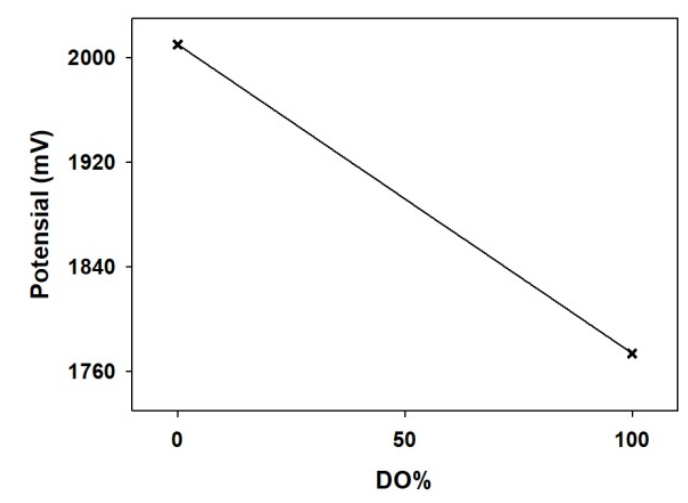

Gambar 5. Kalibrasi Cal0 dan Cal100

$$
\begin{aligned}
& U=2010 \quad 2.36 D O \% \\
& D O \%=\frac{2010 \quad U}{2.36}
\end{aligned}
$$

Berdasarkan Persamaan 2 dapat diketahui nilai DO dalam bentuk persentase (\%) dari pengukuran oksigen terlarut pada fotosintesis Chlorella sp. ketika diberi penambahan variasi konsentrasi POME.

Pengujian vitalitas sel alga sebelum diberi penambahan POME diberi pencahayaan LED ON dan OFF selama 500s untuk melihat respon sel alga ketika diberi pencahayaan. Hasil dari uji fotosintesis alga seperti pada Gambar 6 menunjukkan perubahan potensial pada LED OFF dan ON. Ketika LED OFF, terjadi kenaikan potensial akibat proses respirasi dari sel alga mengkonsumsi oksigen $\left(\mathrm{O}_{2}\right)$ dan saat LED ON terjadi penurunan potensial dikarenakan proses fotosintesis dari sel alga memproduksi oksigen.

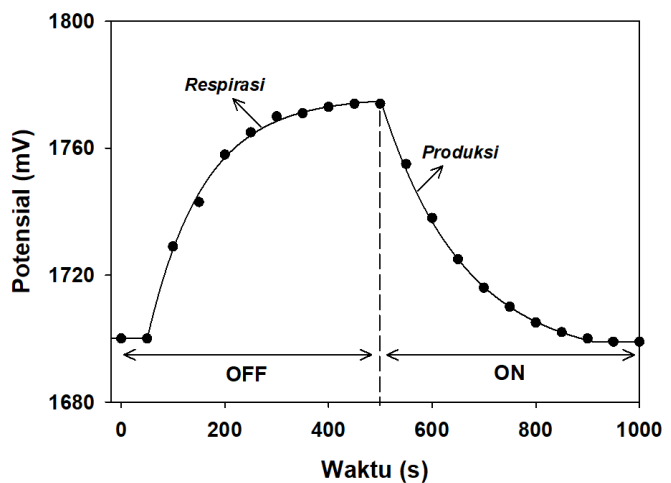

Gambar 6. Kurva respirasi dan fotosintesis alga Chlorella sp.

Hasil analisa pengujian limbah POME menghasilkan nilai COD sebesar $3.500 \mathrm{mg} / \mathrm{L}$ dan $\mathrm{pH}=4$. Kadar COD ini masih dalam keadaan tinggi, dimana semakin tinggi nilai COD terdapat tingkat kepekatan senyawa organik seperti ammonium, nitrogen, fosfor, karbon, dan senyawa organik lainnya menyebabkan kadar oksigen dalam limbah POME semakin rendah (Kamarudin et al., 2015). Hasil pengukuran oksigen terlarut ditunjukkan pada Gambar 7 dan Tabel 2.

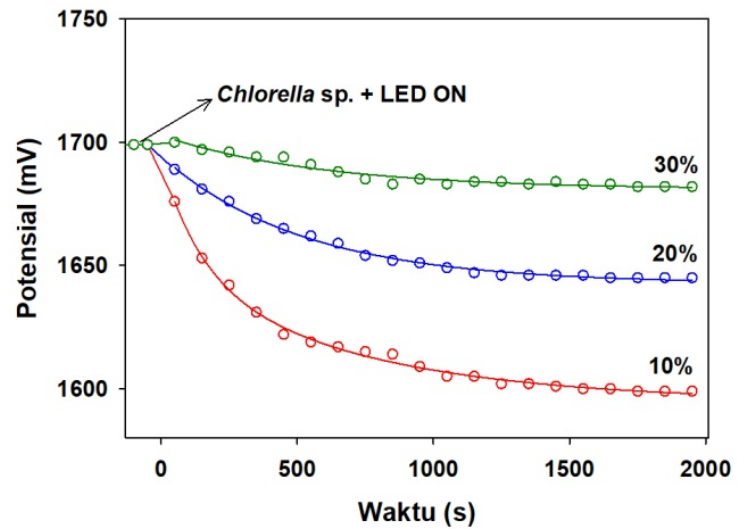

Gambar 7. Hasil pengukuran DO dengan variasi konsentrasi 
Tabel 2. Pengukuran DO dengan Variasi Konsentrasi

\begin{tabular}{ccc}
\hline $\begin{array}{c}\text { Konsentrasi } \\
\text { POME(\%) }\end{array}$ & $\begin{array}{c}\text { Potensial } \\
(\mathbf{m V})\end{array}$ & $\begin{array}{c}\text { DO } \\
\mathbf{( \% )}\end{array}$ \\
\hline 10 & $1599.83 \pm 0.98$ & 174.15 \\
\hline 20 & $1645.33 \pm 0.51$ & 154.66 \\
\hline 30 & $1682.8 \pm 0.83$ & 138.98 \\
\hline
\end{tabular}

Berdasarkan Gambar 7 dan Tabel 2 menunjukkan bahwa sel alga dapat merespon tingkat konsentrasi dari limbah POME yang ditambahkan. Pertumbuhan dan produktivitas sel alga dapat terjadi dengan syarat tercukupinya penyediaan unsur hara seperti karbon, nitrogen, dan fosfordimana nutrisi ini terdapat pada limbah POME (Hariz \& Takriff, 2017).

Hasil yang didapatkan dari pengukuran DO dengan variasi konsentrasi POME menunjukkan semakin tinggi tingkat konsentrasi POME, maka potensial keluaran akan semakin meningkat. Kenaikan potensial keluaran yang dihasilkan menunjukkan rendahnya oksigen terlarut pada pengukuran. Ada beberapa syarat penyebab dari penurunan nilai oksigen terlarut yang dihasilkan. Selain sel alga membutuhkan nutrisi yang cukup, dalam memproduksi oksigen terlarut juga diperlukan pencahayaan yang cukup. Pemberian cahaya yang cukup ketika proses fotosintesis mempengaruhi konversi cahaya menjadi sumber energi dan oksigen yang dihasilkan. Tingkat kekeruhan konsentrasi POME yang gelap berwarna cokelat membatasi cahaya yang masuk ke dalam sampel(Levine et al., 2011). Kekeruhan limbah POME menyebabkan cahaya tidak terdistribusi secara merata sehingga sel alga tidak dapat berfotosintesis dengan baik dalam memproduksi oksigen yang menyebabkan nilai potensialnya semakin naik dan kadar oksigen terlarut semakin turun.

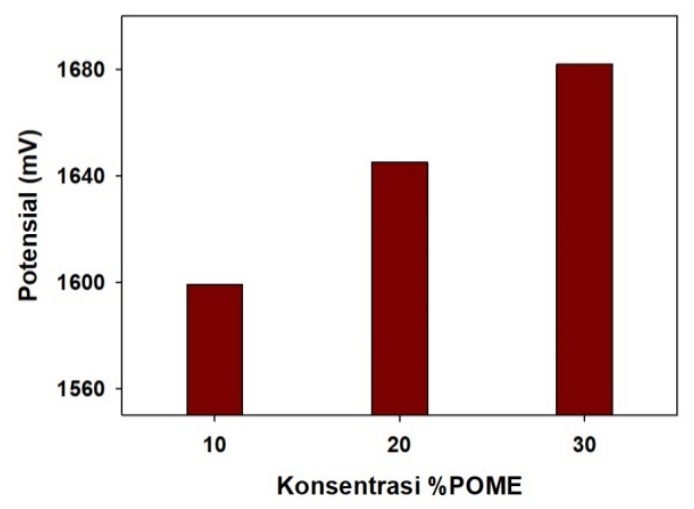

Gambar 8. Kurva konsentrasi POME terhadap potensial

Berdasarkan Gambar 8 dapat dilihat kurva sensitivitas yang menghasilkan nilai sensitivitas sebesar $4 \mathrm{mV} / \%$ POME. Nilai sensitivitas yang dihasilkan menunjukkan bahwa Biochip-G dapat merespon setiap kenaikan 1\% konsentrasi POME sebesar $4 \mathrm{mV}$.

\section{SIMPULAN DAN SARAN}

Identifikasi tingkat konsentrasi limbah POME terhadap sel Chlorella sp. menghasilkan nilai DO $\%$ pada variasi $10 \%, 20 \%$, dan 30\% berturutturut sebesar $174.15 \%, 154.66 \%$, dan $138.98 \%$. Tingkat konsentrasi POME mempengaruhi metabolisme sel alga pada proses pengukuran, dimana semakin tinggi konsentrasi POME, menyebabkan sel alga tidak dapat berfotosintesis akibat kekeruhan dari limbah POME yang membatasi cahaya masuk. Sensitivitas dari BiochipG pada tingkat konsentrasi POME sebesar $4 \mathrm{mV} / \%$ POME. Hal ini menunjukkan bahwa sensor amperometris berbasis Biochip-G dengan bioreseptor Chlorella sp. mampu mendeteksi dan mengidentifikasi tingkat konsentrasi POME. Hasil penelitian ini diharapkan dapat diaplikasikan untuk bidang lingkungan dalam mendeteksi pencemaran limbah pada perairan.

\section{UCAPAN TERIMAKASIH}

Penelitian ini didukung oleh Proyek Aksi ADB UNRI yang telah memberikan dana penelitian melalui Program Hibah Penelitian Mahasiswa Tahun Anggaran 2021.

\section{DAFTAR PUSTAKA}

Ahmad, A., Buang, A., \& Bhat, A. H. (2016). Renewable and sustainable bioenergy production from microalgal co-cultivation with palm oil mill effluent (POME): A review. Renewable and Sustainable Energy Reviews, 65, 214-234.

Ahmad, A. L., Chong, M. F., Bhatia, S., \& Ismail, S. (2006). Drinking water reclamation from palm oil mill effluent (POME) using membrane technology. Desalination, 191(13), 35-44.

Ajab, H., Ali Khan, A. A., Nazir, M. S., Yaqub, A., \& Abdullah, M. A. (2019). Cellulosehydroxyapatite carbon electrode composite for trace plumbum ions detection in aqueous and palm oil mill effluent: Interference, optimization and validation studies. Environmental Research, 176(June), 108563.

Altunoz, M., Allesina, G., Pedrazzi, S., \& Guidetti, E. (2020). Integration of biological waste conversion and wastewater treatment plants by microalgae cultivation. Process Biochemistry, 91, 158-164. 
Cellasys. (2014). BioChip-G (Order No. 08502). 1-7.

Hariz, H. B., \& Takriff, M. S. (2017). Palm oil mill effluent treatment and $\mathrm{CO}_{2}$ sequestration by using microalgaesustainable strategies for environmental protection. Environmental Science and Pollution Research, 24(25), 2020920240.

HiMedia Laboratories. (2015). Algae Culture Broth. 2166.

Kamarudin, K. F., Tao, D. G., Yaakob, Z., Takriff, M. S., Rahaman, M. S. A., \& Salihon, J. (2015). A review on wastewater treatment and microalgal by-product production with a prospect of palm oil mill effluent (POME) utilization for algae. Der Pharma Chemica, 7(7), 73-89.

Karunakaran, C., Bhargava, K., \& Benjamin, R. (2015). Biosensors and bioelectronics. Elsevier.

Levine, R. B., Costanza-Robinson, M. S., \& Spatafora, G. A. (2011). Neochloris oleoabundans grown on anaerobically digested dairy manure for concomitant nutrient removal and biodiesel feedstock production. Biomass and Bioenergy, 35(1), 40-49.

Randrianarison, G., \& Ashraf, M. A. (2018). Microalgae plant (Chlorella sp.) for wastewater treatment and energy production. Ekoloji, 27(106), 1455-1465.

Umar, L., Alexander, F. A., \& Wiest, J. (2015). Application of algae-biosensor for environmental monitoring. Proceedings of the Annual International Conference of the IEEE Engineering in Medicine and Biology Society, EMBS, 2015-Novem, 7099-7102.

Vijayaraghavan, K., \& Ahmad, D. (2006). Biohydrogen generation from palm oil mill effluent using anaerobic contact filter. International Journal of Hydrogen Energy, 31(10), 1284-1291.

Wiest, J., Brischwein, M., Ressler, J., Otto, A. M., Grothe, H., \& Wolf, B. (2005). Cellular assays with multiparametric bioelectronic sensor chips. Chimia, 59(5), 243-246. 